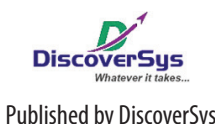

Published by DiscoverSys

\section{The Difference of Patient Satisfaction Between ISO and Non ISO Health Centers in Denpasar}

\author{
A.A.A.A. Candrawati, ${ }^{1,3 *}$ I Ketut Suarjana, ${ }^{2,3}$ Dewa Nyoman Wirawan ${ }^{3,4}$
}

\section{ABSTRACT}

Background and purpose: ISO has been implemented to improve quality of care and patient satisfaction in four health centers in Denpasar. An assessment of the quality of services has been conducted, but there has been no assessment of patient satisfaction. This study determined differences of patient satisfaction between ISO and nonISO centers and related factors.

Methods: The study design was cross-sectional sample survey of 298 respondents; 149 attending ISO clinics and 149 non-ISO clinics. Data were collected using self-administered questionnaires and analyzed with chi square test and logistic regression methods as well as quadrant analysis.

Results: Satisfaction was significantly higher $(p=0.001)$ among ISO health centers $(98.66 \%)$ compared to non-ISO (87.25\%). Satisfaction levels were significantly higher $(\mathrm{p}=0.001)$ among ISO health centers specifically for sub item reliability ( $97.99 \%$ vs $81.21 \%$ ), responsiveness ( $97.32 \%$ vs $82.52 \%)$, assurance ( $98.66 \%$ vs $84.56 \%$ ), empathy ( $97.32 \%$ vs $77.18 \%$ ) and physical appearance ( $97.32 \%$ vs $83.8 \%$ ). Multivariate analysis indicated that factors associated with patients satisfaction were ISO status (adjusted OR=16.56;95\%Cl: 3.87-70.95) and health insurance membership (adjusted OR=3.76; 95\%Cl: 1.38-10.23). Quadrant analysis indicated that sub item politeness, carelessness and untidiness were priority area for improvement among ISO health centers.

Conclusion: Patient satisfaction was significantly higher among ISO health centers. Study findings indicated that sub-items politeness, apparent carelessness and untidiness still to be improved among ISO health centers.

Keywords: patient satisfaction, health centers, ISO, Denpasar

Cite This Article: Candrawati, A.A.A.A. Suarjana, I.K., Wirawan, D.N. 2015. The Difference of Patient Satisfaction Between ISO and Non ISO Health Centers in Denpasar. Public Health and Preventive Medicine Archive 3(1): 28-34. D0l:10.15562/phpma.v3i1.83

\title{
Perbedaan Kepuasan Pasien pada Puskesmas ISO dan Puskesmas Non ISO di Kota Denpasar
}

\section{ABSTRAK}

Latar belakang dan tujuan: ISO diimplementasikan di empat puskesmas Kota Denpasar untuk meningkatkan mutu layanan dan kepuasan pasien. Telah dilakukan penilaian mutu layanan pada puskesmas di Denpasar tetapi belum dilakukan penilaian kepuasan pasien. Penelitian ini dilakukan untuk mengetahui kepuasan pasien pada puskesmas ISO dibandingkan puskesmas non ISO dan faktor yang mempengaruhinya.

Metode: Rancangan penelitian adalah survei sampel cross-sectional

${ }^{1}$ Public Health Centers II South Denpasar,

${ }^{2} S$ chool of Public Health Faculty of Medicine Udayana University, ${ }^{3}$ Public Health Postgraduate Program Udayana University, ${ }^{4}$ Department of Community and Preventive Medicine Faculty of Medicine Udayana University

\section{*Correspondence to:}

A.A.A.A. Candrawati, Public Health Centers II South Denpasar,

aaaacandrawati@yahoo.co.id berdasarkan dimensi mutu secara bermakna $(p=0,001)$ lebih tinggi di puskesmas ISO yaitu kehandalan $(97,99 \%$ vs $81,21 \%)$, ketanggapan (97,32\% vs $82,52 \%)$, jaminan $(98,66 \%$ vs $84,56 \%)$, empati $(97,32 \%$ vs $77,18 \%$ ), penampilan fisik ( $97,32 \%$ vs $83,8 \%$ ). Analisis multivariat menunjukkan bahwa faktor yang mempengaruhi kepuasan pasien adalah status puskesmas ISO dengan adjusted $\mathrm{OR}=16,56$ (95\% Cl: 3,87-70,95) dan status kepesertaan jaminan kesehatan dengan adjusted 0R=3,76 (95\% $\mathrm{Cl}: 1,38-10,23)$. Analisis kuadran menunjukkan bahwa di puskesmas ISO sub-item kesopanan dan ketelitian petugas serta kerapian ruangan merupakan prioritas utama untuk ditingkatkan kinerjanya.

Simpulan: Kepuasan pasien secara bermakna dijumpai lebih tinggi pada puskesmas ISO. Sub-item kesopanan dan ketelitian petugas serta kerapian ruangan masih perlu ditingkatkan kinerjanya di puskesmas IsO. 


\section{PENDAHULUAN}

Puskesmas sebagai pemberi layanan kesehatan terdepan di masyarakat, berfungsi melaksanakan pengembangan di bidang kesehatan, memberdayakan masyarakat dan memberikan layanan terpadu disegala bidang. Puskesmas diharapkan mampu melaksanakan manajemen yang baik, meningkatkan wawasan agar mampu mewujudkan pelayanan yang bermutu. ${ }^{1}$ Pelayanan kesehatan yang bermutu merupakan kebutuhan dasar bagi setiap pasien. ${ }^{2}$ Mutu pelayanan merupakan ukuran dari seberapa baiknya tingkat pelayanan yang mampu diberikan sesuai dengan harapan pelanggan. ${ }^{3}$ ISO merupakan salah satu sarana organisasi untuk meningkatkan mutu suatu layanan agar sesuai dengan standar yang telah ditetapkan. Implementasi standar tersebut merupakan upaya untuk mewujudkan kepuasan pasien. $^{4}$

Kota Denpasar telah mengupayakan peningkatan mutu pelayanan pada empat dari 11 puskesmas sesuai dengan standar ISO 9001; 2008. Puskesmas II Denpasar Selatan memperoleh sertifikat ISO pada tahun 2009, Puskesmas III Denpasar Selatan pada tahun 2012, Puskesmas IV Denpasar Selatan pada tahun 2013 dan Puskesmas II Denpasar Barat pada bulan September 2014. Selama proses untuk mencapai standar ISO dan demikian pula pada tahap awal ketika sertifikat diperoleh, banyak kendala yang dihadapi oleh puskesmas dan masih dijumpai adanya keluhan dan ketidakpuasan pasien. Penilaian terhadap mutu layanan pada semua puskesmas di Denpasar telah dilakukan sejak sebelum sertifikasi ISO, tetapi sama sekali belum pernah dilakukan penilaian tentang kepuasan pasien.

Kepuasan pelanggan perlu diketahui karena pelanggan yang merasa puas dengan layanan, akan datang kembali memanfaatkan pelayanan kesehatan di tempat tersebut. ${ }^{2}$ Penilaian kepuasan pelanggan bisa dilakukan dengan melakukan pengkajian dimensi mutu layanan yang secara langsung bisa menilai kinerja suatu layanan. ${ }^{5}$ Beberapa penelitian tentang hubungan penerapan ISO dengan kepuasan pasien di layanan kesehatan menunjukkan hasil yang tidak konsisten, baik di Indonesia maupun di luar Indonesia. Penelitian dilakukan di India menunjukkan hasil bahwa kepuasan pasien lebih baik pada rumah sakit ISO dibandingkan yang bukan ISO. ${ }^{6}$ Hal yang berbeda didapatkan bahwa kepuasan pasien pada layanan kesehatan tersertifikasi ISO lebih rendah dibandingkan yang tidak tersertifikasi, yang artinya kualitas manajemen ISO tidak mempengaruhi kepuasan pasien. ${ }^{7}$ Penelitian yang dilakukan di Kota Palu mengemukakan bahwa tingkat kepuasan pasien di puskesmas ISO lebih tinggi dibandingkan dengan puskesmas non ISO. ${ }^{8}$ Penelitian yang dilaksanakan di Kota Pekalongan menemukan bahwa penilaian pengunjung puskesmas terhadap mutu layanan tidak berbeda antara puskesmas ISO dengan yang belum ISO. ${ }^{9}$ Penelitian tentang analisis kualitas rumah sakit di Provinsi Bali yang sudah menerapkan ISO dihubungkan dengan harapan pasien. Hasilnya menunjukkan bahwa terdapat kesenjangan antara kualitas pelayanan dengan harapan pasien pada semua rumah sakit yang menerapkan ISO. ${ }^{10}$ Sampai saat ini belum ada penelitian tentang hubungan kepuasan pasien pada puskesmas yang menjalankan ISO di Bali, khususnya di Denpasar.

Penelitian ini dilakukan untuk mengetahui kepuasan pasien pada puskesmas ISO dibandingkan dengan puskesmas non ISO di Kota Denpasar dinilai dari kajian dimensi mutu. Tujuan penelitian adalah untuk mengetahui kepuasan pasien pada puskesmas ISO dibandingkan dengan puskesmas non ISO di Kota Denpasar dan faktor-faktor yang mempengaruhinya.

\section{METODE}

Rancangan penelitian adalah survei sampel crosssectional pada enam puskesmas di Kota Denpasar, yaitu tiga puskesmas ISO (Puskesmas II Denpasar Selatan, Puskesmas III Denpasar Selatan dan Puskesmas II Denpasar Barat) dan tiga puskesmas non ISO (Puskesmas I Denpasar Selatan, Puskesmas I Denpasar Timur dan Puskesmas I Denpasar Barat). Sampel pasien dipilih secara consecutive sebanyak 298 orang yaitu 149 pasien pada puskesmas ISO dan 149 pasien pada puskesmas non ISO.

Data dikumpulkan dengan menggunakan kuesioner yang diisi sendiri oleh pasien. Kepuasan pasien diukur dari penilaian lima dimensi mutu yang meliputi kehandalan, ketanggapan, jaminan, empati dan penampilan fisik yang dijabarkan dalam 29 pertanyaan (kuesioner). Semua pertanyaan menggunakan alternatif jawaban dengan skala likert yaitu dengan skor 1 sampai 4 untuk menilai pengalaman dan harapan pasien. ${ }^{5}$ Jawaban tentang pengalaman pasien terdiri dari empat skor yaitu: $1=$ sangat tidak puas, $2=$ tidak puas, $3=$ puas, $4=$ sangat puas. Jawaban tentang harapan pasien juga terdiri dari empat skor yaitu: $1=$ sangat tidak penting, $2=$ tidak penting, $3=$ penting, $4=$ sangat penting. Tingkat kepuasan pasien diperoleh dari persentase pengalaman dan harapan yang dikategorikan puas bila nilainya $62,51-100 \%$ dan tidak puas bila nilainya $25-43,75 \%{ }^{11}$

Data dianalisis menggunakan program Stata SE 12.1 secara univariat disajikan dalam bentuk 
diagram kartesius untuk mengetahui sub-item dimensi mutu yang perlu ditingkatkan kinerjanya. Selanjutnya dilakukan analisis bivariat dengan uji chi square untuk mengetahui perbedaan karakteristik pasien dan perbedaan tingkat kepuasan pasien baik secara keseluruhan maupun per dimensi mutu pada puskesmas ISO dan puskesmas non ISO. Analisis multivariat dilakukan dengan metode regresi logistik untuk mengetahui faktor yang secara independen mempengaruhi kepuasan pasien.

Penelitian ini telah mendapatkan kelaikan etik dari Komisi Etik Penelitian Fakultas Kedokteran Universitas Udayana/ Rumah Sakit Umum Pusat Sanglah Denpasar.

\section{HASIL}

Responden sebanyak 298 orang (100\%) telah mengisi kuesioner dengan lengkap. Karakteristik reponden disajikan pada Tabel 1 dan terlihat bahwa tidak dijumpai adanya perbedaaan yang bermakna antara responden pada puskesmas ISO dan puskesmas non ISO dalam hal jenis kelamin, penghasilan, pekerjaan dan lama tinggal di Bali ( $p>0,05)$, akan tetapi terdapat perbedaan bermakna dalam hal umur, pendidikan dan status kepesertaan jaminan kesehatan $(\mathrm{p}<0,05)$. Pada puskesmas ISO, lebih banyak responden yang berumur lebih muda dibandingkan puskesmas non ISO yaitu masing-masing 44,97\% dan 31,54\% ( $\mathrm{p}=0,017)$. Pada puskesmas ISO lebih banyak berpendidikan SD/SMP (52,35\%) dibandingkan puskesmas non ISO $(39,60 \%)$ dengan $p=0,027$. Sedangkan dalam hal status kepesertaan, pada puskesmas non ISO lebih banyak responden dengan jaminan kesehatan $(65,10 \%)$ dibandingkan puskesmas ISO (44,30\%) dengan $\mathrm{p}=0,001$.

Pada Tabel 2 disajikan perbedaan kepuasan pasien antara puskesmas ISO dan puskesmas non ISO dalam lima item dimensi mutu yaitu kehandalan, ketanggapan, jaminan, empati dan penampilan pus- kesmas. Perbedaan tertinggi terlihat pada dimensi empati dimana pada puskesmas ISO sebanyak 97,32\% menyatakan puas dan hanya $77,18 \%$ pada puskesmas non ISO

Tabel 1 Karakteristik responden pada puskesmas ISO dan puskesmas non ISO di Kota Denpasar

\begin{tabular}{|c|c|c|c|}
\hline & Puskesmas ISO & Puskesmas non ISO & \\
\hline Variabel & n (\%) & n (\%) & Nilai $\mathbf{p}^{*}$ \\
\hline \multicolumn{4}{|l|}{ Umur } \\
\hline 17-29 tahun & $67(44,97)$ & $47(31,54)$ & 0,017 \\
\hline 30 tahun ke atas & $82(55,03)$ & $102(68,46)$ & \\
\hline \multicolumn{4}{|l|}{ Jenis kelamin } \\
\hline Laki-Laki & $53(35,57)$ & $54(36,24)$ & 0,904 \\
\hline Perempuan & $96(64,43)$ & $95(63,76)$ & \\
\hline \multicolumn{4}{|l|}{ Pendidikan } \\
\hline $\mathrm{SD} / \mathrm{SMP}$ & $78(52,35)$ & $59(39,60)$ & 0,027 \\
\hline SMA ke atas & $71(47,65)$ & $90(60,40)$ & \\
\hline \multicolumn{4}{|l|}{ Penghasilan } \\
\hline$<$ UMR (Rp 1.800.000) & $67(44,97)$ & $69(46,31)$ & 0,816 \\
\hline$\geq \mathrm{UMR}$ & $82(55,03)$ & $80(53,69)$ & \\
\hline \multicolumn{4}{|l|}{ Pekerjaan } \\
\hline Tidak bekerja & $45(30,20)$ & $47(31,54)$ & 0,802 \\
\hline Bekerja & $104(69,80)$ & $102(68,46)$ & \\
\hline \multicolumn{4}{|l|}{ Status kepersertaan } \\
\hline Jaminan kesehatan & $66(44,30)$ & $97(65,10)$ & 0,001 \\
\hline Tidak memiliki jaminan kesehatan & $83(55,70)$ & $52(34,90)$ & \\
\hline \multicolumn{4}{|l|}{ Lama tinggal di Bali } \\
\hline$<5$ tahun & $4(2,68)$ & $3(2,01)$ & 0,500 \\
\hline 5 tahun keatas & $145(97,32)$ & $146(97,99)$ & \\
\hline
\end{tabular}

${ }^{*}$ Uji statistik dengan chi-square dan pada sel dengan nilai expected $<5$ dilakukan dengan Fisher's exact test 
Tabel 2 Kepuasan pasien berdasarkan dimensi mutu pada puskesmas ISO dan puskesmas non ISO di Kota Denpasar

\begin{tabular}{|c|c|c|c|}
\hline Dimensi mutu & $\begin{array}{c}\text { Puskesmas ISO } \\
\text { n (\%) }\end{array}$ & $\begin{array}{c}\text { Puskesmas non ISO } \\
\text { n (\%) }\end{array}$ & Nilai $p$ \\
\hline \multicolumn{4}{|l|}{ Kehandalan } \\
\hline Puas & $146(97,99)$ & $121(81,21)$ & 0,001 \\
\hline Tidak puas & $3(2,01)$ & $28(18,79)$ & \\
\hline \multicolumn{4}{|l|}{ Ketanggapan } \\
\hline Puas & $145(97,32)$ & $123(82,55)$ & 0,001 \\
\hline Tidak puas & $4(2,68)$ & $26(17,45)$ & \\
\hline \multicolumn{4}{|l|}{ Jaminan } \\
\hline Puas & $147(98,66)$ & $126(84,56)$ & 0,001 \\
\hline Tidak puas & $1(1,34)$ & $23(15,44)$ & \\
\hline \multicolumn{4}{|l|}{ Empati } \\
\hline Puas & $145(97,32)$ & $115(77,18)$ & 0,001 \\
\hline Tidak puas & $4(2,68)$ & $34(22,82)$ & \\
\hline \multicolumn{4}{|l|}{ Penampilan fisik } \\
\hline Puas & $145(97,32)$ & $125(83,89)$ & 0,001 \\
\hline Tidak puas & $4(2,68)$ & $24(16,11)$ & \\
\hline
\end{tabular}

Tabel 3 Kepuasan pasien berdasarkan status puskesmas dan karakteristik pasien di Kota Denpasar

\begin{tabular}{|c|c|c|c|}
\hline \multirow[b]{2}{*}{ Variabel } & \multicolumn{2}{|c|}{ Kepuasan pasien } & \multirow[b]{2}{*}{ Nilai $\mathbf{p}^{*}$} \\
\hline & $\begin{array}{l}\text { Puas } \\
\text { n (\%) }\end{array}$ & $\begin{array}{c}\text { Tidak puas } \\
\text { n (\%) }\end{array}$ & \\
\hline \multicolumn{4}{|l|}{ Status pukesmas } \\
\hline Puskesmas ISO & $147(98,66)$ & $2(1,34)$ & 0,001 \\
\hline Puskesmas non ISO & $130(87,25)$ & $19(12,75)$ & \\
\hline \multicolumn{4}{|l|}{ Umur } \\
\hline 17-29 tahun & $105(92,11)$ & $9(7,89)$ & 0,653 \\
\hline 30 tahun keatas & $172(93,48)$ & $12(6,52)$ & \\
\hline \multicolumn{4}{|l|}{ Jenis kelamin } \\
\hline Laki-laki & $100(93,46)$ & $7(6,54)$ & 0,798 \\
\hline Perempuan & $177(92,67)$ & $14(7,33)$ & \\
\hline \multicolumn{4}{|l|}{ Pendidikan } \\
\hline SD/SMP & $133(97,08)$ & $4(2,92)$ & 0,010 \\
\hline SMA ke atas & $144(89,44)$ & $17(10,56)$ & \\
\hline \multicolumn{4}{|l|}{ Penghasilan } \\
\hline$<\mathrm{UMR}$ & $132(97,06)$ & $4(2,94)$ & 0,011 \\
\hline$\geq \mathrm{UMR}$ & $145(89,51)$ & $17(10,49)$ & \\
\hline \multicolumn{4}{|l|}{ Pekerjaan } \\
\hline Tidak bekerja & $85(92,39)$ & $7(7,61)$ & 0,800 \\
\hline Bekerja & $192(93,20)$ & $14(6,80)$ & \\
\hline \multicolumn{4}{|l|}{ Status kepesertaan } \\
\hline Jaminan kesehatan & $155(95,09)$ & $8(4,91)$ & 0,113 \\
\hline Tidak memiliki jaminan kesehatan & $122(90,37)$ & $13(9,63)$ & \\
\hline \multicolumn{4}{|l|}{ Lama tinggal di Bali } \\
\hline$<5$ tahun & $6(85,71)$ & $1(14,29)$ & 0,404 \\
\hline 5 tahun keatas & $271(93,13)$ & $20(6,87)$ & \\
\hline
\end{tabular}

${ }^{\star}$ Uji statistik dengan chi-square dan pada sel dengan nilai expected $<5$ dilakukan dengan Fisher's exact test 
Tabel 4 Adjusted OR kepuasan pasien berdasarkan status puskesmas, umur, pendidikan, penghasilan dan status kepesertaan dalam jaminan kesehatan (jamkes)

\begin{tabular}{|c|c|c|c|}
\hline Variabel & Adjusted OR & $95 \% \mathrm{Cl}$ & Nilai $\mathbf{p}^{*}$ \\
\hline \multicolumn{4}{|l|}{ Status puskesmas } \\
\hline Puskesmas ISO & 16,56 & $3,87-70,95$ & 0,001 \\
\hline Puskesmas non ISO & $\operatorname{Ref}=1$ & & \\
\hline \multicolumn{4}{|l|}{ Umur } \\
\hline 17-29 tahun & 0,74 & $0,28-1,90$ & 0,528 \\
\hline 30 tahun ke atas & $\operatorname{Ref}=1$ & & \\
\hline \multicolumn{4}{|l|}{ Pendidikan } \\
\hline $\mathrm{SD} / \mathrm{SMP}$ & 1,55 & $0,26-9,18$ & 0,627 \\
\hline SMA ke atas & $\operatorname{Ref}=1$ & & \\
\hline \multicolumn{4}{|l|}{ Penghasilan } \\
\hline$<\mathrm{UMR}$ & 3,65 & $0,60-22,12$ & 0,159 \\
\hline$\geq \mathrm{UMR}$ & $\operatorname{Ref}=1$ & & \\
\hline \multicolumn{4}{|c|}{ Kepesertaan jaminan kesehatan } \\
\hline Punya & 3,76 & $1,38-10,23$ & 0,001 \\
\hline Tidak punya & $\operatorname{Ref}=1$ & & \\
\hline
\end{tabular}

$(\mathrm{p}=0,001)$ sedangkan untuk item dimensi mutu lainnya dijumpai perbedaan yang hampir sama.

Pada Tabel 3 disajikan kepuasan pasien berdasarkan status puskesmas dan karakteristik pasien. Terlihat tiga variabel dengan perbedaan bermakna yaitu status puskesmas $(\mathrm{p}=0,001)$, pendidikan $(\mathrm{p}=0,010)$ dan penghasilan $(\mathrm{p}=0,011)$. Kepuasan pada puskesmas ISO terlihat lebih tinggi $(98,66 \%)$ dibandingkan puskesmas belum ISO (87,25\%), sedangkan kepuasan pasien pada pendidikan SD/SMP terlihat lebih tinggi dibandingkan dengan pendidikan SMA ke atas. Kepuasan pasien dengan penghasilan di bawah UMR (97,06\%) lebih tinggi dibandingkan dengan pasien berpenghasilan di atas atau sama dengan $\operatorname{UMR}(89,51 \%)$.

Pada analisis multivariat, variabel yang diikutkan dalam model adalah variabel yang menunjukkan perbedaan yang bermakna baik pada karakteristik responden maupun tingkat kepuasan dengan nilai $\mathrm{p}<0,25$, sehingga terdapat lima variabel yang dimasukkan dalam analisis yaitu umur, status puskesmas, pendidikan, penghasilan dan status kepesertaan dalam jaminan kesehatan.

Pada Tabel 4 terlihat bahwa variabel yang bermakna mempengaruhi kepuasan pasien adalah status puskesmas dalam ISO dengan adjusted $\mathrm{OR}=16,56(95 \% \mathrm{CI}: 3,87-70,95)$ dan kepesertaan pasien dalam jaminan kesehatan dengan adjusted $\mathrm{OR}=3,75$ (95\%CI: 1,38-10,26).

Berdasarkan analisis kuadran pada puskesmas ISO, terdapat tiga sub-item di kuadran A (prioritas utama diperbaiki) meliputi kesopanan petugas dan ketelitian petugas (dimensi jaminan), kerapian ruangan (dimensi penampilan fisik), 11 sub-item di kuadran B (pertahankan), 13 sub-item di kuadran C (prioritas rendah) dan dua sub-item di kuadran D (berlebihan). Pada puskesmas non ISO, terdapat delapan sub-item di kuadran A meliputi kecepatan pelayanan pemeriksaan, ketepatan pelayanan pemeriksaan, (dimensi kehandalan), kejelasan informasi petugas tentang penyakit pasien, kecepatan tindakan petugas saat pasien membutuhkan (dimensi ketanggapan), ketelitian petugas (dimensi jaminan), perhatian petugas yang sama tanpa membedakan status sosial ekonomi pasien (dimensi empati), kesiapan alat yang dipakai (dimensi penampilan fisik).

\section{DISKUSI}

Dalam penelitian ini diperoleh bahwa pasien yang menyatakan puas pada pelayanan puskesmas secara bermakna lebih tinggi pada puskesmas ISO (98,66\%) dibandingkan dengan puskesmas non ISO $(87,25 \%)$. Hal ini menunjukkan bahwa puskesmas yang sudah melaksanakan ISO di Kota Denpasar telah mampu melaksanakan ISO dengan baik. Kepuasan yang lebih tinggi pada puskesmas ISO bisa disebabkan karena beberapa hal antara lain: sarana prasarana yang digunakan untuk pelayanan telah dikalibrasi setiap tahun dan implementasi ISO diaudit setiap enam bulan secara internal. Audit internal dilakukan sebagai persiapan dilaksanakannya audit setiap tahun oleh pihak eksternal, untuk memastikan apakah 
puskesmas tersebut masih layak menyandang sertifikat ISO. Puskesmas ISO juga memiliki target kinerja di masing-masing layanan untuk memacu kinerjanya dan dilakukan evaluasi setiap bulan. Semua dokumen baik internal maupun eksternal sudah dikendalikan untuk memudahkan penelusuran apabila diperlukan dan semua kegiatan yang dilaksanakan lebih teratur karena mengikuti prosedur yang sudah ditetapkan. Pada puskesmas non ISO, semua kegiatan tersebut di atas tidak dilaksanakan secara optimal.

Walaupun tingkat kepuasan pasien pada puskesmas ISO lebih baik dibandingkan puskesmas non ISO, tetapi ada beberapa hal yang masih perlu ditingkatkan. Berdasarkan analisis kuadran dalam penelitian ini didapatkan tiga sub-item yang menjadi prioritas utama untuk diperbaiki kinerjanya yaitu kesopanan, ketelitian petugas dan kerapian ruangan. Hal ini mungkin karena terlalu banyak beban pekerjaan untuk memenuhi persyaratan ISO sehingga mengurangi kesopanan dan ketelitian petugas serta kerapian ruangan. Pada puskesmas non ISO, terdapat delapan sub-item yang perlu ditingkatkan yaitu: kecepatan, ketepatan pemeriksaan, kejelasan informasi tentang penyakit pasien, kecepatan tindakan, ketelitian, perhatian yang sama tanpa membedakan status sosial ekonomi pasien dan kesiapan alat yang dipakai.

Bila dibandingkan dengan hasil penelitian lain, hasilnya ada yang sesuai ada pula yang tidak sesuai. Hasil penelitian ini sesuai dengan hasil penelitian Syamsura tentang tingkat kepuasan pasien terhadap kualitas pelayanan Puskesmas II Denpasar Selatan dengan tingkat kepuasan pasien sebesar $89,36 \% .^{12}$ Pada saat penelitian, puskesmas di Kota Denpasar belum melaksanakan ISO. Penelitian tentang pengaruh ISO terhadap kepuasan pasien di Provinsi Bali dilakukan oleh Nurcahya yang menunjukkan adanya kesenjangan antara kualitas pelayanan dengan harapan pasien pada semua rumah sakit yang menjalankan ISO dan untuk kelima dimensi mutu pelayanan. ${ }^{10}$ Namun penelitian tersebut hanya menunjukkan adanya kesenjangan tanpa membandingkan dengan rumah sakit tanpa ISO. Hasil penelitian ini juga sesuai dengan penelitian yang dilakukan oleh Lasa, dkk di Kota Palu, menggunakan rancangan deskriptif, dan menunjukkan bahwa tingkat kepuasan puskesmas ISO lebih tinggi $(94,34 \%)$ dibandingkan puskesmas non ISO $(89,25 \%) .{ }^{8}$ Demikian juga pada penelitian yang dilakukan oleh Wartana dengan rancangan cross-sectional, menunjukkan perbedaan yang bermakna kepuasan pasien pada puskesmas ISO dan non ISO $(p<0,05)$ dengan lebih banyak pasien yang puas pada puskesmas ISO. ${ }^{13}$ Hasil yang sama juga dijumpai pada penelitian di rumah sakit di India yaitu dijumpai kepuasan yang lebih tinggi pada rumah sakit dengan ISO dibandingkan rumah sakit yang tidak ISO. ${ }^{6}$

Beberapa penelitian lain menunjukkan hasil yang berbeda, antara lain penelitian oleh Yuniarti dengan rancangan penelitian case control menunjukkan bahwa tidak terdapat hubungan kepuasan pengunjung antara puskesmas yang bersertifikat ISO dan yang belum bersertifikat ISO $(\mathrm{p}=0,762){ }^{9}$ Perbedaan tersebut kemungkinan disebabkan karena perbedaan rancangan penelitian. Penelitian lain yang juga menunjukkan hasil yang berbeda adalah penelitian cross-sectional yang dilakukan di Iran oleh Maryam, et al, menunjukkan bahwa kepuasan pasien pada primary health care (PHC) tanpa ISO secara bermakna $(\mathrm{p}<0,01)$ lebih tinggi $(83,3 \%)$ dibandingkan PHC dengan ISO $(70,2 \%){ }^{7}$ Perbedaan hasil penelitian ini kemungkinan karena perbedaan karakteristik wilayah di Iran dengan di Denpasar.

Bila dilihat per masing-masing dimensi mutu, perbedaan bermakna dijumpai pada semua item dimensi mutu dan paling tinggi pada dimensi empati. Temuan ini sesuai dengan hasil penelitian yang dilakukan oleh Lasa, dkk di Kota Palu mengenai tingkat kepuasan pasien yang mendapatkan sub-item dimensi empati lebih tinggi pada puskesmas ISO (96,52\%) dibandingkan puskesmas non ISO $(87,64 \%) .^{8}$ Berdasarkan nilai adjusted OR, status puskesmas ISO merupakan variabel yang paling berpengaruh terhadap kepuasan pasien. Temuan ini sesuai dengan penelitian yang dilakukan oleh Lasa, dkk dan Wartana yang menunjukkan adanya pengaruh penerapan ISO terhadap peningkatan tingkat kepuasan pasien. ${ }^{8,13}$ Tingkat kepuasan dipengaruhi juga oleh status kepesertaan pasien dalam jaminan kesehatan dengan nilai adjusted OR 3,76. Hasil yang sesuai dijumpai pada penelitian yang dilakukan oleh Widyastomo, Dyana dan Suharmadji bahwa kepuasan pasien dipengaruhi oleh kepemilikan jaminan kesehatan. ${ }^{14-16}$

Dari hasil penelitian ini bisa direkomendasikan bahwa puskesmas perlu meningkatkan kualitas pelayanan sesuai dengan standar ISO dalam upaya untuk meningkatkan kepuasan pasien. Selain itu direkomendasikan pula bahwa puskesmas yang telah menjalankan ISO masih tetap harus meningkatkan kualitas pelayanannya sesuai dengan hasil evaluasi yang dilaksanakan.

Penelitian ini hanya dilaksanakan di puskesmas Kota Denpasar dan karena itu tidakbisa digeneralisir ke puskesmas di wilayah lainnya, baik di Provinsi Bali maupun wilayah lainnya di Indonesia. 


\section{SIMPULAN}

Kepuasan pasien pada puskesmas ISO dijumpai lebih baik dibandingkan puskesmas non ISO namun masih perlu ditingkatkan kinerjanya dalam hal kesopanan dan ketelitian petugas serta kerapian ruangan. Faktor yang dijumpai berpengaruh terhadap kepuasan pasien adalah status puskesmas ISO dan non ISO serta kepemilikan jaminan kesehatan.

\section{UCAPAN TERIMA KASIH}

Terima kasih disampaikan kepada semua pasien yang telah bersedia menjadi responden, petugas pengumpul data, kepala puskesmas serta jajarannya dan pihak lain yang telah membantu pelaksanaan penelitian ini.

\section{DAFTAR PUSTAKA}

1. Poerwani S. Forum Mutu Pelayanan Kesehatan Indonesia; 2005.

2. Hamid R, Darmawansyah, Balqis. Hubungan Mutu Pelayanan Kesehatan dengan Kepuasan Pasien Rawat Jalan di Puskesmas Batua Kota Makasar; 2013 Available at: http://repository.unhas.ac.id/handle/123456789/5724 [Accessed October 19, 2013].

3. Tjiptono dan Candra G. 2005. Service, Quality and Satisfaction. Available at: http://www.library.upnvj.ac.id/ index.php? $\mathrm{p}=$ show_detail\&id=3677 [Accessed October 5, 2014].

4. Setyawan W. Prinsip Dasar ISO 9001: 2008; 2008: p.1-4.

5. Supranto J. Pengukuran Tingkat kepuasan untuk Menaikkan Pangsa Pasar. Jakarta: PT. Rineka Cipta; 2011.

6. Jha, N and Rana, S. A Comparative Study of Patient Satisfaction Between ISO Certified and Non-Certified Health Care Units; 2012. Available at: http://iuu.ac/ download-pdf/MgtDec12.pdf [Accessed September 16, 2014].
7. Maryam, H., Yasdi, V.F., Maybodi ,F.B. Costumer' Satisfaction with Primary Health Care: Comparison of Two District Health Centers with and Without ISO Certificate In Kerman University Of Medical Sciences; 2013. [Accessed September 27, 2014].

8. Lasa N, Sudirman, Sakung JM. Studi Komparatif Kepuasan Pasien Puskesmas Berstandar ISO dan Puskesmas Non Standar ISO di Kota Palu; 2012. Available at: http://www. scribd.com/doc/128367656/7-Najma-Lasa

9. Yuniarti. Mutu Pelayanan Kesehatan Menurut Persepsi Pasien di Puskesmas Tersertifikasi dan Belum Tersertifikasi ISO 9001: 2000 di Kota Pekalongan”. Fakultas Ilmu Kesehatan Masyarakat, Pekalongan: Universitas Pekalongan; 2000: p.31-41.

10. Nurcaya NI. Analisis Kualitas Pelayanan Rumah Sakit di Provinsi Bali Denpasar. Denpasar: Universitas Udayana; 2008.

11. Witriasih A. Perbedaan Tingkat Kepuasan Pasien Peserta PT Askes (Persero) Cabang Denpasar Terhadap Pelayanan Puskesmas dan Dokter Keluarga di Kota Denpasar (tesis). Denpasar: Universitas Udayana; 2012.

12. Syamsura DS. Analisis Tingkat Kepuasan Pasien terhadap Kualitas Pelayanan Puskesmas II Denpasar Selatan (skripsi). Denpasar: Universitas Udayana; 2006.

13. Wartana K. Kepuasan Pasien terhadap Pelayanan Kesehatan: Perbandingan antara Puskesmas Bersertifikat ISO dengan Puskesmas yang Belum Bersertifikat ISO (tesis) Jogjakarta: Universitas Gadjah Mada; 2010.

14. Widyastomo J, Rachmawati YL, Aly AR. Hubungan Karakeristik Pasien dengan Tingkat Kepuasan terhadap Pelayanan di Poli Gigi dan Mulut Rumah Sakit Umum Daerah Dr. Saiful Anwar Malang (skripsi). Malang: Universitas Brawijaya; 2013.

15. Dyana PC. Hubungan Pelayanan JKN dan Karakteristik Pasien terhadap Kepuasan Pasien Rawat Jalan: Studi di Fasilitas Kesehatan Tingkat Pertama dan Apotik Program Rujuk Balik (tesis) Jogjakarta: Universitas Gajah Mada; 2015.

16. Suharmadji. Analisis Tingkat Kepuasan Pasien Rawat

17. Jalan Umum Puskesmas di Pekanbaru ; 2003.

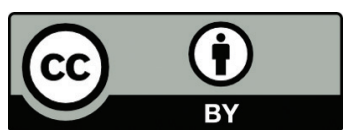

This work is licensed under a Creative Commons Attribution 